\title{
ONLINE TRUST MECHANISMS: A DOMAIN STUDY OF ONLINE AUCTIONS
}

\author{
Glenn Bewsell \\ School of Information Systems and Technology \\ University of Wollongong \\ Email: gbewsell@uow.edu.au
}

\begin{abstract}
This research investigates mechanisms that impact trust at online auctions. A qualitative study is discussed within this paper to identify mechanisms that impact trust at online auctions. The mechanisms identified are discussed within normative and grounded theoretical approaches to trust.

A result of this discussion I seek to answer the question: what factors do people perceive as important to increase online trust prior to an online transaction? This discussion will help professionals understand the factors that emerge from normative and grounded theoretical approaches to online trust research. A better understanding of online trust adds to the body of theory and can be used to improve the design of online auctions.
\end{abstract}

\section{INTRODUCTION}

Online auction users are reliant on technology. Technology allows items to be offered for auction and transactions to be formed between online auction users for the exchange of goods and consideration. Technology is able to replace people, and users may not know when they are dealing with another person or a piece of technology such as a computer program.

At online auctions, users are represented by an online identity and users can be virtually anonymous to each other (Zhao et al., 2006). These users may be real, misrepresented, honest or opportunistic. Buyers and sellers at online auctions are vulnerable and trust is required when entering into a transaction. A better understanding of trust is required, especially in relation to online auction transactions.

The motivation for this research is to identify mechanisms that impact online auction trust. Online auction trust is considered as a broad construct as it "spans the end-to-end aspects of e-business .... It extends beyond the web site and includes all electronic networks used by the firm" (Shankar et al., 2002 p.326).

This paper presents an analysis of qualitative data collected as part of an experimental research study that investigated trust in online auctions. This research seeks to answer the question: What mechanisms do people perceive as important to increase online trust prior to a consumer-toconsumer online auction transaction?

This research is important for practitioners and researchers to gain a better understanding of trust. Trust is an important, broad and little understood construct in e-commerce which needs to be more 
effectively understood in order to build better e-commerce models and to attract people to transact rather than browse online.

\section{THEORETICAL PERSPECTIVE}

This section provides the theoretical perspective relevant to this research. Trust and power are believed to be two key constructs in understanding what drives and inhibits people to transact online. These constructs are discussed in turn.

\section{Trust}

At online auctions, buyers and sellers can be virtually anonymous (Zhao et al., 2006) to each other and trust is required due to the possibility of exploitation and exclusion (Lind, 1995; van den Bos et al., 2002). Trust is the "consumer's willingness to rely on the seller and take action in circumstances where such action makes the consumer vulnerable to the seller" (Jarvenpaa et al., 1999). A buyer at an online auction is faced with the choice to "cede authority and subsume to the power" (van den Bos et al., 2002 p.53) of a seller and bid with the purpose of entering into a transaction. The objects of trust that are of interest to this research are "the things that can be trusted" (Nooteboom, 2002 p.10) and those things that people perceive will increase online trust.

The normative model of trust used in this research is presented in Figure 1. This normative model of trust includes: i) trusting beliefs; ii) attitude towards trust; iii) intention to trust; and iv) behavioural trust. This model of trust appears consistent with the Theory of Planned Behaviour (Fishbein \& Ajzen 1975; Ajzen 2005) where a relationship exists between attitudes and behaviour. The five bases of trust identified within the model of trust are: personality-based trust; institution-based trust; cognitive-based trust; calculative-based trust; and knowledge-based trust. Each of these bases of trust will be discussed.

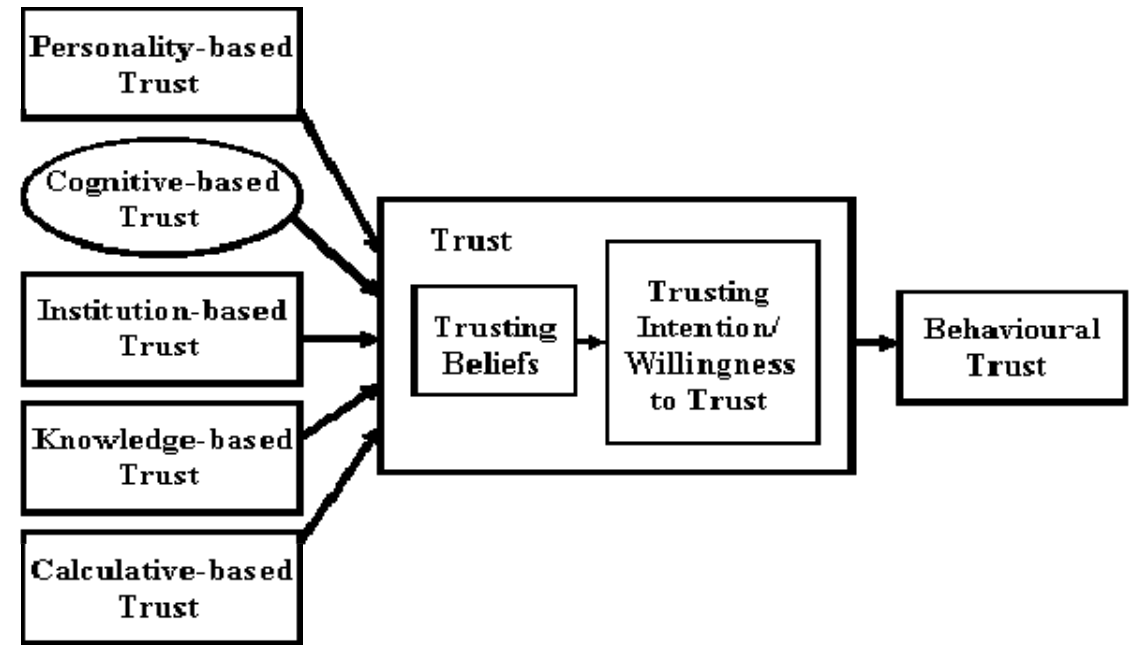

Figure 8: Normative Model for Trust (Based on McKnight et al., 1998) 
Personality-based trust is a "general tendency to trust others (Rotter, 1967)” (McKnight et al., 1998 p.475), a "trust propensity" (Koufaris \& Hampton-Sosa 2002 p.379) or a "general willingness based on extended socialization to depend on others"' (Ridings et al., 2002 p.278). This propensity or tendency to trust others indicates that people will have a tendency to trust an online auction site and an online auction transaction.

Institution-based trust "reflects the security one feels about a situation because of guarantees, safety nets, or other structures (Shapiro, 1987; Zucker, 1986)” (McKnight et al., 1998 p.475). Institutionbased trust or institutional trust contains three dimensions: i) situational normality or the situation appears normal such as websites that appear normal (Bhattacherjee 2002; Koufaris \& HamptonSosa 2002; McKnight et al., 1998; McKnight et al., 2002; Pavlou \& Gefen 2004; Pavlou et al., 2003); ii) structural assurances such as third-party structures and contracts (McKnight et al., 1998; McKnight et al., 2002); and iii) facilitating conditions such as conditions that match market expectations including shared standards, beliefs, and values (McKnight et al., 1998). Institutionbased trust will help to assure online auction users that the online auction looks normal and appropriate structures are in place to support online auction transactions. The major dimensions of institution-based trust of interest to this research are situational normality and structural assurances, refer to Table 1.

\begin{tabular}{|c|c|c|c|c|c|c|}
\hline \multicolumn{5}{|c|}{ Structural Assurances } & \multicolumn{2}{|c|}{ Situation Normality } \\
\hline Guarantees & $\begin{array}{c}\text { Safety } \\
\text { Nets }\end{array}$ & Recourse & Regulations & $\begin{array}{c}\text { Other } \\
\text { procedures }\end{array}$ & $\begin{array}{c}\text { Normal } \\
\text { Appearance } \\
\end{array}$ & $\begin{array}{c}\text { Proper } \\
\text { Order }\end{array}$ \\
\hline $\begin{array}{l}\text { Credit card } \\
\text { guarantees }\end{array}$ & $\begin{array}{l}\text { Escrow } \\
\text { services } \\
\text { such as } \\
\text { PayPal }\end{array}$ & $\begin{array}{l}\text { Legal } \\
\text { system, } \\
\text { contracts, } \\
\text { promises, } \\
\text { plans for } \\
\text { contingenc } \\
\text { ies and } \\
\text { sanctions } \\
\text { specified } \\
\text { (eg. site } \\
\text { expulsion) }\end{array}$ & $\begin{array}{l}\text { Technical and } \\
\text { professional } \\
\text { standards, } \\
\text { codes of } \\
\text { ethics, } \\
\text { standards of } \\
\text { practice, } \\
\text { precedents, } \\
\text { judicial } \\
\text { decisions and } \\
\text { international } \\
\text { law }\end{array}$ & $\begin{array}{l}\text { Buyer driven } \\
\text { certification, } \\
\text { feedback } \\
\text { mechanisms } \\
\text { for buyers and } \\
\text { sellers, } \\
\text { relationships } \\
\text { in the same } \\
\text { markets and } \\
\text { community, } \\
\text { certifications } \\
\text { and } \\
\text { accreditations }\end{array}$ & $\begin{array}{l}\text { Web site } \\
\text { appearance, } \\
\text { presentation } \\
\text { and } \\
\text { specification } \\
\text { of the item } \\
\text { being } \\
\text { auctioned } \\
\text { (images, } \\
\text { description } \\
\text { and } \\
\text { specifications) }\end{array}$ & $\begin{array}{l}\text { Privacy, } \\
\text { security, } \\
\text { conditions } \\
\text { of use, } \\
\text { user } \\
\text { agreement } \\
\text { s, } \\
\text { identifiers } \\
\text { and } \\
\text { socially } \\
\text { constructe } \\
\text { d roles }\end{array}$ \\
\hline
\end{tabular}

Table 2: Institution-based Trust

(Based on Bhattacherjee 2002; Koufaris \& Hampton-Sosa, 2002; Luhmann, 1979; McKnight et al., 1998; McKnight et al., 2002; Nooteboom, 2002; Pavlou \& Gefen, 2004; Pavlou et al., 2003;

Shapiro, 1987)

Situation normality is a belief based on a normal appearance and proper order of things (Bhattacherjee 2002; Koufaris \& Hampton-Sosa, 2002; McKnight et al., 1998; McKnight et al., 2002; Pavlou \& Gefen, 2004; Pavlou et al., 2003). At online auctions things such as website appearance, the presentation of items, user agreements and socially constructed roles should provide indicators for people to assess whether things appear normal and orderly. Within situation normality, this research considers the distinction between the normal appearance of the online auction site and the proper order of the site that would facilitate a successful transaction. 
Structural assurances are the safeguards in place such as guarantees, safety nets, regulations, promises, legal recourse and other procedures (McKnight et al., 1998; McKnight et al., 2002; Nooteboom 2002; Pavlou \& Gefen, 2004; Pavlou et al., 2003; Shapiro, 1987). Structural assurances at online auctions may include: credit card guarantees provided by a financial institution when payment is made by credit card; safety nets provided by escrow services; and transactional feedback from other users.

Cognitive-based trust is based on "rapid, cognitive cues or first impressions" (McKnight et al., 1998 p.475) or "shared cognitive structures, which yield empathy" (Nooteboom, 2002 pp.12-13). In Figure 1, cognitive-based trust is represented as an oval to indicate cognitive processes (McKnight et al., 1998). Two types of cognitive-based trust are categorisation processes and illusions of control, refer to Table 2. Categorisation processes can provide high levels of trust in an online auction where the other user shares common values, shares common goals, have a good reputation and possess certain stereotypes that are appealing (Kramer, 1999; McKnight et al., 1998). Furthermore illusions of control may also provide high levels of trust at an online auction such as some small action to confirm ones initial trusting belief (McKnight et al., 1998).

\begin{tabular}{|l|l|}
\hline \multicolumn{1}{|c|}{ Categorisation Processes } & \multicolumn{1}{c|}{ Illusions of Control } \\
\hline $\begin{array}{l}\text { Shares common values, shares common goals, } \\
\text { certain stereotypes that are appealing and } \\
\text { good reputation. Similar interests (e.g. } \\
\text { product, types, auctions, email hosts, type of } \\
\text { replies) }\end{array}$ & $\begin{array}{l}\text { Questions to the seller (e.g. responsiveness to } \\
\text { questions, quality of reply), and ability to take } \\
\text { transaction off the auction site. }\end{array}$ \\
\hline
\end{tabular}

Table 3: Cognitive-based Trust

Knowledge-based trust is based on an interaction history and the first hand knowledge that parties have of each other (McKnight et al., 1998) or observation of the trustee (Nooteboom, 2002). Buyers and sellers that have previous interactions with each other are able to base their perceptions of trust on this knowledge. At an online auction, the buyer and seller are virtually anonymous and are not expected to have firsthand knowledge of each other; however, they may have firsthand knowledge of the online auction site.

Calculative-based trust is a "trusting stance" (McKnight et al., 1998 p.475) or a "calculative selfinterest" (Nooteboom, 2002 p.13). A buyer or a seller may consider that things will probably "turn out best when they are willing to depend on" (McKnight et al., 1998 p.478) the transaction. A buyer or a seller may consider or calculate the potential benefits and losses of the other party's cooperation or non-cooperation. Benefits can encourage good behaviour and penalties can discourage bad behaviour. At an online auction, a benefit is good transaction feedback and a penalty is a fine or a suspended trading account.

\section{Power}

Power is a broad construct that includes various types of power. French \& Raven (1959) identified various types of social power as: coercion; reward; legitimate (position); expert; referent; and informational power. At an online auction the buyer, the seller, and potentially the mediator may use power to influence other parties and try to resolve a dispute.

Power may be more balanced or less balanced. Power will be more balanced if the resources are more equally shared between the parties, and power will be less balanced if one party has access to more of the resources. The resources can include the goods, the consideration, or special skills and 
knowledge. The balance of power related to an online auction transaction changes as goods and consideration are transferred between the parties. Power at an online auction is "the ability to influence the decisions or actions of others" (Thorelli, 1986 p.38). The buyer and the seller may try to communicate to influence each other or they may not. At an online auction the buyer and seller may trust a powerful third party such as the auction site or an independent third party.

A relationship between power and trust has been supported by previous researchers and these researchers support that power is antecedent to trust (Duarte \& Davis, 2000; Geyskens et al., 1998; Thorelli, 1986).

This section has provided the theoretical perspective for this research. Trust, the bases of trust and power have been discussed in relation to online auctions, and a relationship between power and trust has been established.

\section{RESEARCH METHODOLOGY}

To investigate what mechanisms people perceive as important to increase online trust in an online auction situation, qualitative feedback was requested as part of an experimental study. This paper discusses this qualitative feedback in order to shed some contextual 'light' on the motivation of the research subjects. The qualitative feedback includes items that may increase the participant's level of trust in dealing with sellers at an online auction.

\section{The Experimental Scenario}

Undergraduate and postgraduate participants from a leading university in Sydney were provided a booklet for use in the judgmental experimental design study. Each booklet contained an introduction, instructions, scenario, a set of screenshots of the online auction website and a questionnaire. Each participant was randomly allocated one of four levels of power.

The introduction, instructions and basic scenario were the same for each booklet. These sections introduced the participants to the study, familiarised participants with the setting, provided any information required for the study and advised each participant how to proceed.

The Introduction presented an online auction as the domain of interest and allowed information to be provided to participants to control for their level of knowledge. The type of online auction presented to participants was the normal or English auction where a seller placed an item for sale and buyers submitted bids on the item. For a bid to be successful, it must be the highest bid at the close of the auction and exceed the minimum acceptable price (that is the reserve). An example of this type of auction which participants may be familiar with was eBay ${ }^{\mathrm{TM}}$ (eBay 2006).

In the Introduction, participants were introduced to the U.S. Federal Trade Commission's (FTC's) report about online auction fraud. Reports such as the FTC's report were in the public domain and online auctions were becoming more newsworthy. Prior to the experiment participants may or may not be aware of this report; however, the general level of awareness of problems related to online auction fraud was expected to increase over time. The risk of not providing public domain information from the report was that participants would have unequal levels of knowledge and participants would become aware of this report or similar reports some time later. The provision of pertinent public information from the report provided some control over the participant's level of knowledge and this may avoid the need to rerun multiple experiments as the level of knowledge in the public domain increased. The participant's level of knowledge was a variable in the outer core of the research model and control of this variable was reasonable. One question in the questionnaire tested for the participant's level of knowledge. 
The Instructions section advised participants a research purpose, the level of analysis that would be performed, information in response to participant's potential privacy concerns and how to complete the booklet.

The online auction site was carefully presented within the booklet to avoid constructs of disinterest conflicting with constructs of interest. For example information about the seller was not disclosed on purpose. The online auction site had a generic domain name 'Auction.com.au' that did not exist on the Internet. The online auction site was described within the booklet as relatively new and had been operating for a short period of time. Participants had not used the site previously and would not know anyone who had used the auction site. Site reputation and Word-of-Mouth (WOM) referrals were non-existent and therefore controlled.

The Scenario described the setting, advised the participant the layout of the balance of booklet, asked the participant to familiarise themselves with the booklet and website printouts, asked the participant to decide whether to place a bid at the online auction, and then asked the participant to complete the questionnaire.

Every booklet included screenshots of the online auction site's home, conditions of use, privacy, security and registration web pages. Each web page included navigation tabs for clarity. Every booklet included one of four different variations of dispute resolution procedures. The four variations of dispute resolution procedures were used to support a factorial research design, to manipulate power and to affect trust levels within the experiment. One variation of the booklet was used for control and dispute resolution was not mentioned within this booklet. The other three variations of the booklet contained one of three different dispute resolution web pages.

The four variations, treatments or manipulations of dispute resolution procedures and power are presented in Table 3. Each treatment contains different dispute resolution functionality and 'power to resolve' a dispute. This table acknowledges that power may reside in different places, the relationships between the parties may change and the bases of power may be different. A higher 'power to resolve' was expected to resolve more disputes, and a lower 'power to resolve' was expected to resolve less disputes. Some manipulations included the availability of a third-party role, as a third-party was expected to increase 'situation normality' by providing a proper order to an online auction and mastery over ambiguous circumstances. Mediation was also expected to increase structural assurances by providing parties access to a form of recourse. 'Situation normality' and structural assurances were expected to reduce complexity and increase trust.

\begin{tabular}{|c|c|c|}
\hline Treatment & Dispute Resolution Functionality & $\begin{array}{l}\text { 'Power to } \\
\text { Resolve' }\end{array}$ \\
\hline M1 & Process is implied (Participants perceptions) & \\
\hline M2 & Buyer and seller in a dyadic relationship & Low \\
\hline M3 & $\begin{array}{l}\text { Mediator available for a triadic relationship (Mediator can recommend a } \\
\text { resolution) }\end{array}$ & Medium \\
\hline M4 & $\begin{array}{l}\text { Mediator available for a triadic relationship (Mediator can make and enforce } \\
\text { their final decision to solve conflict) }\end{array}$ & High \\
\hline
\end{tabular}

Table 4: Experimental Manipulations of Power with Dispute Resolution Mechanisms

Every participant was assigned the role of the buyer. Participants were asked to assume that they needed to purchase an item (a motor vehicle) of the type offered at an online consumer-to-consumer auction, so that the participant's needs and wants were established. Participants understood the 
seller to be a private individual and that the current bid reflected a fair price. As the auction was closing soon, participants needed to decide whether to place a bid.

A motor vehicle was expected to have a high potential for information uncertainty compared with that of a commodity item (Akerlof, 1970; Ba \& Pavlou, 2002; Mishra et al., 1998). Information related to a motor vehicle could include condition, colour, accessories, type, make, model, year, and the expertise of the seller.

Once a participant was familiar with the website and scenario they completed the questionnaire. The questionnaire consisted of three main parts: i) a general section to capture respondent demographics such as gender, previous participation in online auctions, and knowledge of online auctions; ii) a quantitative section that captured empirical data; and iii) a qualitative section that captured additional insights into a participant's beliefs. This paper focuses on the qualitative section of the study. In the qualitative section of the questionnaire, participants were able to identify any items that they felt would help increase or decrease trust in dealing with sellers at the online auction.

Mechanisms identified by participants to increase or decrease online trust were abstracted or grouped into key themes. These themes emerged from the data as in a grounded theoretical approach or were derived from the literature as in a normative approach. To allow themes to emerge from the data, the qualitative data was codified using IHMC CmapTools version 4.09 software (IHMC, 2006). The responses were codified as concepts, the concepts were arranged to highlight commonality and abstracted to form themes. The concepts and abstractions were linked and verbs used to help explain these linkages. The abstractions were then arranged around the main concept of online trust. This technique allowed the concepts and themes to emerge from the data in a 'bottom up' approach. The normative view of online trust was considered by placing participant's qualitative responses into the main normative themes of online trust derived from the theory; refer to Tables 1 and 2.

The qualitative responses were also analysed using participant demographics to determine if differences existed between the types of participants.

\section{QUALITATIVE DATA ANALYSIS AND RESULTS}

No discernable differences were found in the demographics between the thirty-seven participants that responded to the qualitative section of the research and the one hundred and one participants that participated in the overall research design. The qualitative results presented here appear to be representative of all of the study's participants. Results will now be discussed based on the thirtyseven qualitative responses received.

$27.0 \%$ of all participants had participated in one or more online auction transactions. Participants had purchased or sold items in 92 online auction transactions and 5 of these transactions had resulted in a dispute. In other words a dispute had been experienced once in every 18.4 online auction transactions. Participant demographics for this study are presented in Table 4.

On average participants $(\mathrm{P})$ rated their knowledge of online auctions slightly lower than 'average' as shown in Figure 2. Participants that had no previous transactions (NPT) at an online auction rated themselves on average as having poor to average knowledge of online auctions whereas those that had previous transactions (PT) rated themselves on average as having average to good knowledge of online auctions and closer to good knowledge. Participants that had purchased and sold (PS) items at an online auction on average rated themselves as having more knowledge (good to very good) than respondents that had only purchased $(\mathrm{Pu})$ at an online auction (average to good). Participants that had completed more than five transactions $(>5)$ on average rated themselves as having more 
knowledge (good) than people that have less than five transactions $(<5)$ as average to good. The averages support that a person that had completed more online auction activities perceived themselves as having more knowledge of online auctions than a person that had completed less online auction activities. A person that had previously visited, interacted with sellers, bid, purchased, and sold at an online auctions had more experience and greater perceived knowledge than a person that had not participated in all of these activities. In general a participant's reported knowledge of online auctions appeared to increase as the types and number of their activities increased.

\begin{tabular}{|c|c|c|c|}
\hline \multicolumn{2}{|c|}{ Demographic Variable } & \multicolumn{2}{|l|}{$\begin{array}{l}\text { Participants } \\
(\mathrm{n}=37)\end{array}$} \\
\hline & & Frequency & $\%$ \\
\hline \multirow[t]{3}{*}{ Gender } & Male & 24 & 64.9 \\
\hline & Female & 11 & 29.7 \\
\hline & Missing data & 2 & 5.4 \\
\hline \multirow{4}{*}{$\begin{array}{l}\text { Online } \\
\text { Auction } \\
\text { Activity }\end{array}$} & $\begin{array}{c}\text { Participants that } \\
\text { purchased }\end{array}$ & 10 & 27.0 \\
\hline & Participants that sold & 4 & 10.8 \\
\hline & $\begin{array}{l}\text { Participants with no } \\
\text { experience }\end{array}$ & 27 & 73.0 \\
\hline & Missing data & 0 & 0.0 \\
\hline
\end{tabular}

Table 5: Study Demographics

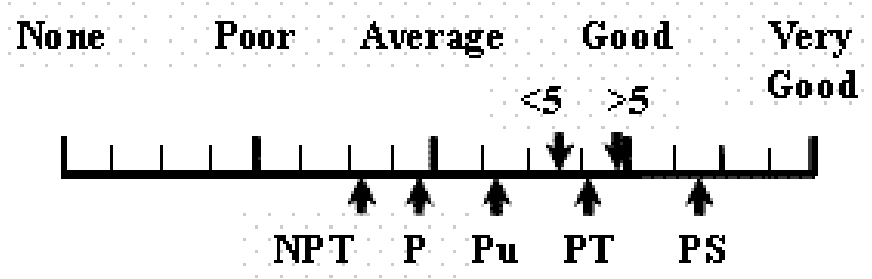

Figure 9: Knowledge Rating

Legend: $\mathrm{P}=$ Participants, NPT $=$ No Previous Transactions, $\mathrm{PT}=$ Previous Transactions, $\mathrm{Pu}=$ Purchased, PS $=$ Purchased and Sold, $>5=$ Greater than 5 Transactions, $<5=$ Less than 5 Transactions.

Concept mapping tools (IHMC 2006) were used to analyse the qualitative data. Eight major themes emerged from the concept mapping techniques as: sellers (35.1\%); processes (32.4\%); assurances/guarantees (32.4\%); references/testimonials (18.9\%); website reputation and associations (21.6\%); security (10.8\%); services (8.1\%); and site presentation (5.4\%). These themes and associated concepts are presented in the Concept Map of Online Trust, refer to Figure 3. Each theme will now be discussed in turn. 


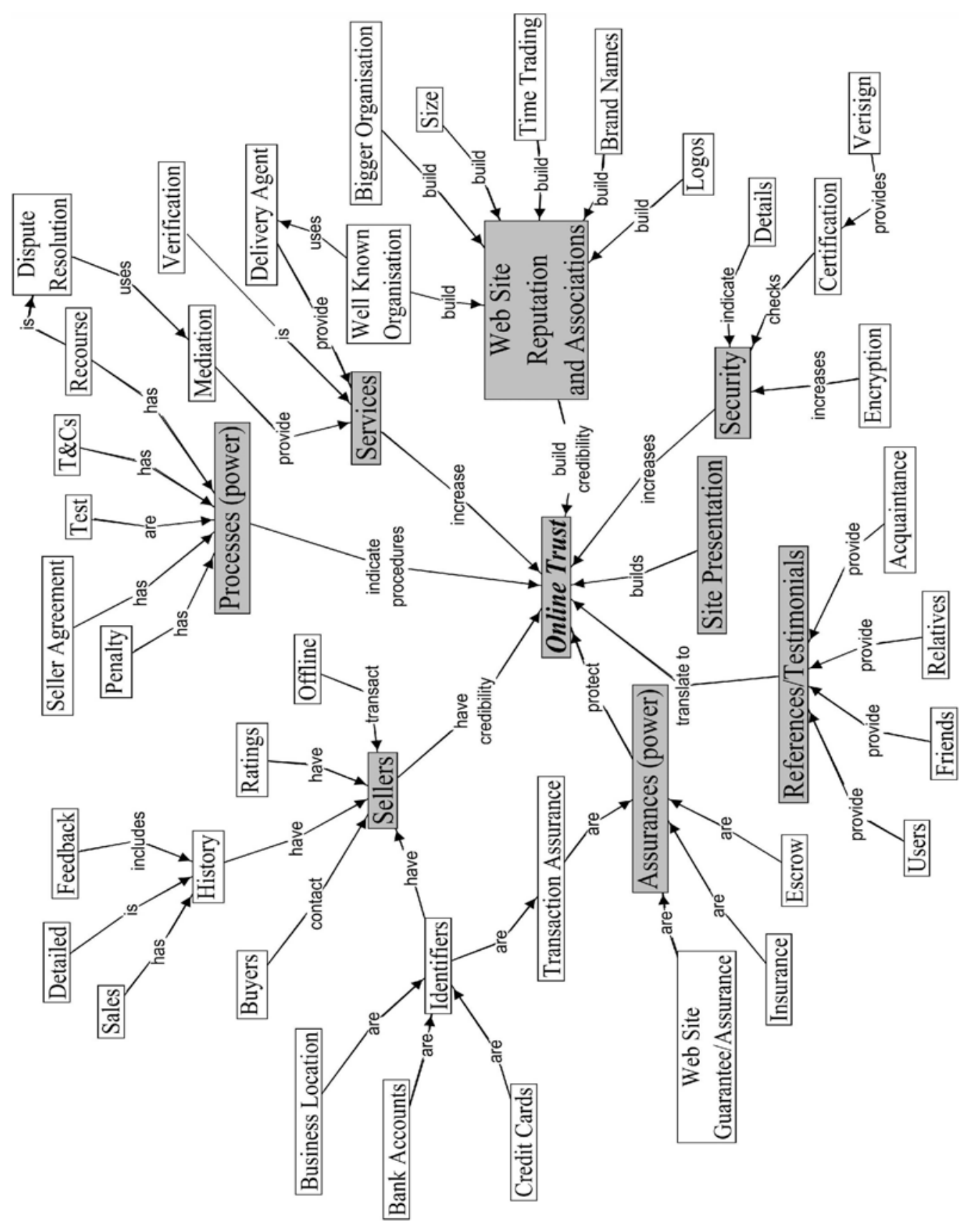


The theme of sellers included history details, identification of the seller, contact with the seller, sellers' ratings, and transacting with sellers offline. To increase online trust, participants identified the need for: better access to seller histories of previous sales, detailed sales information, feedback related to those transactions and seller's ratings; better identification of sellers with linkages to bank account details, business locations and credit card details; the ability to contact the seller offline to decide if the seller is trustworthy; and physical contact with the seller and display of the item at the seller's premises.

The processes theme related to terms and conditions, the seller's agreement, dispute resolution processes, recourse, binding processes and more detailed processes. To increase online trust, participants identified the need for: more detailed terms and conditions; the seller's agreement with the online auction site; clear dispute resolution processes; binding arbitrary mediation; and processes that provide an ability to sue and penalise the seller.

Assurances/guarantees theme was the auction site taking responsibility for transactions, positive declarations, assurances similar to credit card guarantees, escrow and insurance. To increase online trust, participants identified the need for: the online auction site to provide binding guarantees and assurances; access to insurance in case of a dispute; and safe transaction assurances such as credit cards, third party providers and escrow services.

References/testimonials theme was references and testimonials from friends, acquaintances, relatives and other users. To increase online trust, participants mainly needed advice from users, friends, relatives and acquaintances who had used this auction site before. Other items identified were a past user forum and trustworthy testimonials.

The website reputation/associations theme related to the size of the site, how long the online auction had been operating and other organisations that were associated with the site. To increase online trust, participants identified the need for the online auction site: to have been in business longer; to be more well-known; to be a larger organisation; and to have associations with wellknown and trustworthy companies.

The security theme was secure systems and data encryption for information transfer. To increase online trust, participants identified the need to clearly identify details related to security such as encryption and security certifications.

The services theme was required for mediation services, services to verify goods, and trusted delivery services. To increase online trust, participants identified the need for services that supported the transaction such as mediation services, verification services and trustworthy delivery services.

Finally, the presentation theme related to the presentation and layout of the website. Two participants identified that the layout and presentation of the site and web pages could be improved to increase online trust.

The qualitative data and results were analysed based on participant demographics collected as part of the questionnaire. The participant demographics considered were: transaction history such as transacted or not transacted; gender; and other such as previous disputes.

\section{Transaction History}

Participants that had not previously transacted online were concerned with: site reputation/associations (25.9\%); the seller (22.2\%); references/testimonials (22.2\%); processes (18.5\%); and assurances/guarantees (18.5\%). Participants that had previously transacted online were 
mainly concerned with the seller (70.0\%), assurances/guarantees (40.0\%) and penalties (20.0\%). Penalties was a concept and related to the processes theme.

Common items between the groups were transaction specific items related to the seller, assurances/guarantees and processes themes. Although these items were common between the groups the percentages differ greatly. Seventy percent (70.0\%) of participants that had previously transacted at an online auction were concerned with the seller and forty percent $(40.0 \%)$ concerned with assurances/guarantees, whereas the percentages in the other group were much smaller. The participants that had not previously transacted at an online auction were concerned with more generic themes related to the auction site and these were: site reputation; site associations; and references/testimonials.

\section{Gender}

Feedback received was checked for similarities and differences between the genders. Major items to improve trust for both genders were assurances/guarantees and seller themes.

Males most frequently suggested that items associated with the seller (37.5\%) were required to increase trust. The seller's history, identification of the seller, contact with the seller, other buyer's ratings of the seller, information related to the seller's previous sales and other seller information may help to increase trust. Assurances/guarantees theme (29.2\%) was the second most frequently suggested theme to increase trust. The assurances/guarantees theme suggested by males included auction site guarantees, safe transaction methods such as visa, escrow and insurance services. Other ways to increase trust were associations/reputation (12.5\%), processes (12.5\%), and security $(12.5 \%)$ related items.

Females most frequently suggested that references or testimonials (36.4\%) from family, friends and others were necessary to increase trust. Auction site reputation and associations (36.4\%) was the next most frequently suggested theme to increase trust. Reputation and associations related to how long the auction site had been trading, becoming a world-wide known site, and becoming bigger like eBay. Seller (27.3\%) related items were also identified by females as a way to increase trust. The seller related items included: other buyers providing an indication of the seller's trustworthiness; seller history; and contacting the seller to buy offline after finding the price is good. Processes (18.2\%) were mentioned by females as a theme to increase trust.

Sellers, processes and association/reputation were common to both groups but the percentages were quite different. Whereas males were mainly concerned with transaction specific items, females were more concerned with the auction site reputation and associations.

\section{Other}

Other groupings of participants were considered based on previous disputes and research manipulations.

Participants that had previously experienced a dispute thought that the seller $(100.0 \%)$ was the major item to increase trust. Seller related items included: the ability to make contact with the seller; the ability to identify the seller; and the physical display of the item for auction at the owner's premises. The auction site should be able to sue the seller, if necessary.

Other analysis considered groups based on the research manipulations or experimental treatments assigned. The results based on these groups were very similar. It appeared that the manipulation presented to participants had not impacted the items considered to increase trust. 


\section{Normative Approach}

The normative approach was considered and the qualitative responses were placed within theoretical groupings (Tables 1 and 2), refer to Table 5. The highest rating categories were: other procedures (37.8\%); categorisation (32.4\%); recourse (32.4\%); and proper order (29.7\%). The two highest rated response items were: references from friends and acquaintances with seven responses; and procedures to capture and access detailed information related to the seller with six responses. Items that received three responses were: seller identifiers; improved registration procedures; trusted third-parties; associations and affiliation with known brand names; site reputation; auction site liability; encryption and security certification; and enhanced credibility or verification of goods and services.

No participants identified regulations to increase trust at an online auction.

When participant demographics were considered the four highest rating categories were evident throughout, except for experienced online auction users.

Males identified: other procedures (50.0\%); proper order (37.5\%); and recourse (33.3\%). In the highest rated category males identified the need to: improve user registration by linking registered users to a credit card or bank account; enhance credibility or verification of goods and services; and capture and access detailed seller information. In addition, males identified that online auction sites needed to accept liability for transactions formed by them.

Females identified: categorisation (54.5\%); and recourse (27.3\%). In the highest rated category females identified the need for: references from friends and acquaintances; association or affiliation such as brand names and trusted companies; and site reputation.

Experienced online auction users identified that other procedures (70.0\%) and recourse (30.0\%) were major items to increase online trust. These experienced users identified that credit card and bank account details were important for user registration and procedures were required to capture and access detailed seller information. Experienced online auction users had not identified any items that would be categorised as proper order. Proper order was notable for its absence.

Inexperienced online auction users identified: proper order (40.7\%); categorisation (37.0\%); recourse (33.3\%); and other procedures (25.9\%).

\section{DISCUSSION}

This section will discuss potential users of online auctions; the grounded theoretical approach to online auction trust; the normative approach to online auction trust; compare the two approaches to online auction trust; the potential impact of the manipulation; and demographic differences.

One non-user of online auctions indicated that they would not trust an online auction because they did not trust the online environment. This finding supported the claim of Tan \& Thoen (2002) that people needed to trust the virtual environment to engage in an online transaction. This participant was not likely to become a user of online auctions; the other twenty-six (26) non-users were considered potential users of online auctions. In other words $96.3 \%$ of the non-users were potential users of online auctions if sufficient improvements were incorporated to increase online auction trust.

The grounded theoretical approach used concept mapping and this approach allowed the data to be organised in new ways that provided new insights into online auction trust. Three of the eight 
themes were identified for discussion: assurances/guarantees; the importance of building trust through sellers; and processes.

\begin{tabular}{|c|c|c|}
\hline Category & $\begin{array}{l}\text { No. of } \\
\text { Respondents (\% of } \\
\text { participants) }\end{array}$ & Sub-Category (No. of responses per sub-category) \\
\hline $\begin{array}{l}\text { Other } \\
\text { Procedures }\end{array}$ & $14(37.8 \%)$ & $\begin{array}{l}\text { Procedures to capture \& access detailed seller information (6) } \\
\text { Improved registration procedures: use credit card/bank } \\
\text { account (3) } \\
\text { Encryption \& security information certification (3) } \\
\text { Enhance credibility or verification of goods \& services (3) } \\
\text { Procedure for fines (1) } \\
\text { Safe transaction procedures (1) } \\
\text { Delivery methods (1) }\end{array}$ \\
\hline Categorisation & $12(32.4 \%)$ & $\begin{array}{l}\text { References from friends \& acquaintances (7), } \\
\text { Association or affiliation eg brand names, trusted companies } \\
(3), \\
\text { Site reputation (time trading, size, trustworthiness) (3) } \\
\text { Feedback related to sellers (2), } \\
\text { Location of seller (1) }\end{array}$ \\
\hline Recourse & $12(32.4 \%)$ & $\begin{array}{l}\text { Auction site liable and no immunity (3), } \\
\text { Clear procedures for recourse (2) } \\
\text { Mediation service (1) } \\
\text { Dispute resolution on seek court action (1) } \\
\text { Precise terms \& conditions (1) } \\
\text { Actions taken against those that do not follow instructions or } \\
\text { guides (1) } \\
\text { Be able to sue the seller (1), } \\
\text { Assurances for both sides (1), } \\
\text { Dispute resolution statistics (1) }\end{array}$ \\
\hline Proper Order & $11(29.7 \%)$ & $\begin{array}{l}\text { Trusted } 3^{\text {rd }} \text { Party (3), } \\
\text { Seller Id./Seller Information (3), } \\
\text { Security, encryption, safe transaction (2), } \\
\text { Terms and conditions, sellers agreement (2), } \\
\text { Mediation service (1) }\end{array}$ \\
\hline $\begin{array}{l}\text { Normal } \\
\text { Appearance }\end{array}$ & $4(10.4 \%)$ & $\begin{array}{l}\text { Site layout (1), } \\
\text { Case history (1), } \\
\text { More attractive web pages (1), } \\
\text { Provision of statistics, examples, information on dispute } \\
\text { resolution (1) }\end{array}$ \\
\hline Calculative & $4(10.4 \%)$ & $\begin{array}{l}\text { Lower value items (3) } \\
\text { Seller fines (1) }\end{array}$ \\
\hline $\begin{array}{l}\text { Illusions of } \\
\text { Control }\end{array}$ & $3(8.1 \%)$ & $\begin{array}{l}\text { Contact with seller (2), } \\
\text { User forum (1), }\end{array}$ \\
\hline Guarantees & $2(5.4 \%)$ & $\begin{array}{l}\text { More guarantees - binding (1), } \\
\text { Credit card guarantee (1) }\end{array}$ \\
\hline Safety Nets & $2(5.4 \%)$ & $\begin{array}{l}\text { Escrow (1), } \\
\text { Insurance (1) }\end{array}$ \\
\hline Regulations & $0(0.0 \%)$ & \\
\hline
\end{tabular}

Table 6: Qualitative Responses A Priori 
The assurance/guarantees theme included: transaction assurances; web site guarantees; and safety nets such as insurance and escrow services. Users wanted improved identification of users and online auction site assurances to increase online auction trust. Users appeared to want an online auction site to demonstrate their respect for online auction communities, to be more responsible for transactions formed by their site and to provide adequate assurances that demonstrated the auction site's trust for their communities. The assurance theme included elements of recourse. Zhao et al., (2006) expressed the concern that "[sellers] can take the money and run" (p.72), and these assurances should help to reduce this concern and increase trust. This concern may be true for items that have a high information asymmetry or all online auction items.

The importance of building trust through sellers was supported with things that were linked to sellers, rather than the more personal qualities and personal assurances of a seller that could be assessed in an offline or face-to-face transactional context. This finding supported Tan \& Thoen (2002) that electronic commerce trust is 'trust in the transaction'.

The processes themes were: the online auction site taking more responsibility in ensuring that any transactions formed were completed to the satisfaction of the parties involved; providing suitable dispute resolution procedures; assisting customers with dispute resolution; providing access to thirdparty mediation; and ensuring that sellers accepted their responsibilities. Some online auction sites do provide some level of access to third party mediation services; however, this research indicated that well integrated operational processes were required to support dispute resolution mechanisms and recourse. This finding may support that processes need to be fair (van den Bos et al., 2002).

Further theme abstraction supported that power was a higher level theme. Power included the themes of assurances/guarantees and processes. This finding supported: that people transacting at online auctions would like a powerful party that was not part of the immediate transaction to ensure that sellers were able to be identified; that processes were in place and operational; and that powerful parties provided assurances and guarantees. Powers that were provided at online auctions may need to be balanced so that buyers do not "engage in strategic behaviour" (Zhao et al., 2006 p.72).

This research supported that better assurances and guarantees would improve users' perceptions of trustworthiness and impact their trust beliefs. Governmental regulations were not identified by this research as an item to increase online auction trust. The lack of identified regulation improvements may indicate: that existing regulations did not impact online auction sites because sites limited their responsibility to the formation of transactions; that existing regulations were adequate to support online auction transactions; or that online auction sites had the best ability to increase trust at online auctions. This research supported the concept of guardians of trust and the need for guardians to deter or limit opportunism (Shapiro, 1987) and that auction sites were perceived to be the primary guardian of trust.

Many of the processes identified could be considered as control procedures and perceived behavioural controls. For example, better seller identification can make it easier for a buyer to physically identify a seller. This finding is supported by Tan \& Thoen (2002) where sufficient controls need to be in place and these control procedures need to be understood and Shapiro (1985) acknowledged the need for control of impersonal trust. Perceived behavioural controls are supported by the Theory of Planned Behaviour (Fishbein \& Ajzen 1975; Ajzen 2005). TPB supported relationships between perceived behavioural controls and trust as an attitude and perceived behavioural controls and intention to trust (Fishbein \& Ajzen 1975; Ajzen 2005). 
The normative approach identified 'other procedures', categorisation, recourse and proper order as the major items to increase trust. 'Other procedures', recourse and proper order supported structural assurances within institution-based trust, and categorisation supported cognitive-based trust. In other words, most items identified by this research supported that institution-based trust and cognitive-based trust impacted online auction trust.

The allocation of things identified by participants to categories and sub-categories pertaining to the normalised view of online trust was not intuitive. For example security could have indicated: i) a proper order within situation normality; ii) a technical standard or standard of practice and hence a regulation within structural assurances; or iii) an accreditation or a certification and hence another procedure within in structural assurances.

This research indicated that the integrated model of online trust proposed by Zhang \& Zhang (2005) could be investigated as a potentially better model of trust. This integrated model of trust included institution-based trust factors consistent with the normative model of trust used within this research and the trustor, trustee and trustee website as trust factors.

Themes were compared between the grounded theoretical and normative approaches to online auction trust. The comparison indicated similarities and differences between these two approaches to trust.

Items to increase online auction trust were able to be categorised using each approach to trust. Both approaches identified recourse as an item to increase online auction trust. The assurance/guarantees theme from the grounded theoretical approach included the guarantees, safety nets and elements of recourse themes from the normative approach. Clear procedures for recourse and the ability to hold the auction site liable with no immunity were identified as major items within recourse. Recourse can be considered as a control procedure and a service within the grounded theoretical mapping approach. The need for clearer and better understood control procedures is supported by Tan \& Thoen (2002).

The grounded theoretical approach highlighted the seller, power and assurances as items to increase online trust. The normative model of trust highlighted other procedures, categorisation, recourse and proper order as items to increase online trust.

The normative approach tended to hide the importance of sellers across the normative themes, appeared less intuitive and appeared more limited in explaining more anonymous consumer-toconsumer online auction transactions.

This research did manipulate dispute resolution functionality and the manipulation may have drawn each participant's attention to the potential for a dispute and the potential need to resolve a dispute; however, participants assigned to higher levels of dispute resolution functionality identified just as many recourse items as did other participants. The results did not support that the manipulation resulted in participants overestimating recourse as an item to increase online auction trust. This research supported that the potential for a dispute was salient prior to an online auction transaction.

Demographic differences found were gender and transaction history. Whereas, males appeared to rely on their own assessments of transaction specifics, females tended to look to opinions of others. Females relied on references from acquaintances, relatives, friends, and users in their decision to participate in online auctions. This gender difference may be characteristic of all motor vehicle sales rather than for online auction transactions. Bell (1967) suggests that one answer may lie with "variations in exposure to information about automobiles" (p.48). Auction categories may have a greater appeal to particular genders, groups of users may be more knowledgeable about items within 
certain auction categories and designs that catered for their target audience would be expected to perform better than designs that did not. Online auction sites that were flexible and able to cater for these user differences were expected to provide higher levels of trust and do better than sites that do not. User group differences were supported as an important consideration in the usability and design of online auctions.

The findings of this research are important because they represent both non-users and users of online auctions. One explanation for the research findings based on Shankar et al., (2002) was that potential and existing users of online auctions would like proper systems in place that extended beyond the forming of transactions to the setting, monitoring and maintenance of standards of practice within the online auction community. This research supported that a better model of trust is required to better understand online auction transactions. A model of online auction trust grounded within TPB may be better than existing models of online auction trust adapted from other domains.

\section{LIMITATIONS AND FUTURE RESEARCH}

The data collected was qualitative information received in conjunction with an experimental research design. All care was taken to make the research design as real as possible. The site and information presented was based on actual online auction sites. Only $5.4 \%$ of the participants identified that improving site presentation and layout would lead to an increase in online trust. No participants that had previously used an online auction site identified site presentation or layout as a possible factor to increase online trust.

This research was exploratory, reduced data into themes and was intended to provide new insights into online auction trust. This research does not represent the population of potential and existing users of online auctions.

Future research is required: to include a wider population of online auction users and to include data that represents all stages of online auction transactions; to confirm and further explore usability requirements at online auctions; and to develop a better and more specific model of online auction trust grounded within TPB.

\section{CONCLUSIONS}

This qualitative research identified mechanisms that people perceived as important to increase online auction trust prior to a transaction using normative and grounded theoretical approaches to trust. Key trust mechanisms identified were assurances/guarantees, sellers and processes. These mechanisms supported that trust in the overall transaction was required rather than trust in any one person or thing.

User differences were identified as an important consideration for the usability and design of online auction sites. A disconnection existed between items currently provided at online auctions and items that users and potential users and males and females would like provided at online auctions. Whereas existing users were focused on the transactional level characteristics, potential users were concerned with both the auction site and transactional level characteristics; and whereas males placed a high focus on seller themes and assurances, the most frequently suggested theme by females was references and testimonials.

This research compared and contrasted normative and grounded theoretical approaches to online auction trust. At an online auction, the normative approach appeared less intuitive, tended to hide the importance of sellers and have limitations in helping to understand trust. This research supported 
that the grounded theoretical approach to trust can help theorists and practitioners to better understand online auction trust.

\section{ACKNOWLEDGMENTS}

The author gratefully acknowledges the helpful comments of Dr. Deborah Bunker and Associate Professor Rodger Jamieson on this article.

\section{REFERENCES}

Ajzen, I. (2005) Attitudes, Personality and Behavior (2nd ed.), Open University Press, Maidenhead.

Akerlof, G. A. (1970) “The Market for 'Lemons’: Quality Uncertainty and the Market Mechanism”, The Quarterly Journal of Economics, Vol 84 No 3, pp 488-500.

Ba, S., and Pavlou, P.A. (2002) "Evidence of the Effect of Trust Building Technology in Electronic Markets: Price Premiums and Buyer Behavior”, MIS Quarterly, Vol 26 No 3, pp 243-268.

Bell, G.D. (1967) “Self-confidence and Persuasion in Car Buying”, Journal of Marketing Research, Vol 4 No 1, pp 46-52.

Bewsell, G.R. (2008) “An Investigation of Mechanisms that Impact Trust: A Domain Study of Online Auctions”, Unpublished Doctoral Dissertation, The University of New South Wales.

Bhattacherjee, A. (2002) “Individual Trust in Online Firms: Scale Development and Initial Test”, Journal of Management Information Systems, Vol 19 No 1, pp 211-241.

Duarte, M., and Davies, G. (2000) “Trust as a Mediating Variable in a Complex Model of Channel Member Behaviour”, IMP Group, URL

http://www.bath.ac.uk/imp/pdf/139_DuarteDavies.pdf, (Accessed date 23 June 2003).

eBay (2006) eBay, Retrieved 18 April 2006, 2006, from the World Wide Web: http://www.ebay.com/

Fishbein, M., and Ajzen. I. (1975) Belief, Attitude, Intention, and Behavior: An Introduction to Theory and Research, Addison-Wesley, Massachusetts.

French, J. R. P., Jr., and Raven, B.H. (1959) The Bases of Social Power, In D Cartwright (eds) Studies in Social Power, University of Michigan Press, Michigan.

FTC (2006) Top 10 Consumer Fraud Complaint Categories, Federal Trade Commission Release, URL http://www.ftc.gov/opa/2006/01/topten.htm, (Dated 25 January, 2006, Accessed date 20 February 2007).

Geyskens, I., Steenkamp, J-B.E.M., and Kumar, N. (1998) “Generalizations about Trust in Marketing Channel Relationships Using Meta-Analysis”, International Journal of Research in Marketing, Vol 15 No 3, pp 223-248.

IFCC (2001) Internet Auction Fraud, FBI \& National White Collar Crime Centre, Auction Fraud Report, URL http://www1.ifccfbi.gov/strategy/AuctionFraudReport.pdf, (Accessed date 14 June 2003).

IHMC (2006) CmapTools, Institute for Human and Machine Cognition (IHMC), URL http://cmap.ihmc.us, (Accessed date 22 February 2007). 
Jarvenpaa, S. L., Tractinsky, N., and Vitale, M. (1999) “Consumer Trust in an Internet Store: A Cross-Cultural Validation”, Journal of Computer Mediated Communication, December, Vol 5 No 2.

Katsh, E., Rifkin, J., and Gaitenby, A. (2000) “E-Commerce, E-Disputes, and E-Dispute Resolution: In the Shadow of eBay Law”, Ohio State Journal on Dispute Resolution, Vol 15 No 3, pp 705-734.

Koufaris, M., and Hampton-Sosa, W. (2002) Initial Perceptions of Company Trustworthiness Online: A Comprehensive Model and Empirical Test, CIS Working Paper Series Zicklin School of Business, URL http://cisnet.baruch.cuny.edu/papers/cis200211.pdf, (Accessed date 30 April 2003).

Kramer, R. M. (1999). Trust and Distrust in Organizations: Emerging Perspectives, Enduring Questions. Annual Review of Psychology, Vol 50, pp 569-598.

Lind, E. A. (1995) Social Conflict and Social Justice: Some Lessons from the Social Psychology of Justice. Leiden University Press, Leiden.

Luhmann, N. (1979) Trust and Power, John Wiley and Sons, New York.

McKnight, H., Cummings, L.L. and Chervany, N.L. (1998) “Initial Trust Formation in New Organizational Relationships”, The Academy of Management Review, Vol 23 No 3, pp 473490.

McKnight, D. H., and Choudhury, V. and Kacmar, C. (2002) "Developing and Validating Trust Measures for e-Commerce: An Integrative Typology”, Information Systems Research, Vol 13 No 3, pp 334-361.

Mishra, D. P., Heide, J.B., and Cort, S.G. (1998) “Information Asymmetry and Levels of Agency Relationships”, Journal of Marketing Research, Vol 35 No 3, pp 277-295.

Nooteboom, B. (2002) Trust: Forms, Foundations, Functions, Failures and Figures. Edward Elgar, Cheltenham.

Pavlou, P. A., and Gefen, D. (2004) "Building Effective Online Marketplaces with Institution-Based Trust”, Information Systems Research, March, Vol 15 No 1, pp 37-59.

Pavlou, P. A., Tan, Y-H., and Gefen, D. (2003) “The Transitional Role of Institutional Trust in Online Interorganizational Relationships”, Proceedings of the 36th Hawaii International Conference on System Sciences.

Ridings, C. M., Gefen, D., and Arinze, B. (2002). Some Antecedents and Effects of Trust in Virtual Communities. Journal of Strategic Information Systems, Vol 11 No 3-4, pp 271-295.

Shankar, V., Urban, G.L., and Sultan, F. (2002) “Online Trust: A Stakeholder Perspective, Concepts, Implications, and Future Directions”, Journal of Strategic Information Systems, December, Vol 11 No 3-4, pp 325-344.

Shapiro, S. P. (1987) “The Social Control of Impersonal Trust”, American Journal of Sociology, November, Vol 93 No 3, pp 623-658.

Tan, Y.-H., and Thoen, W. (2002) "Formal Aspects of a Generic Model of Trust for Electronic Commerce”, Decision support Systems, Vol 33 No 3, pp 233-246.

Thorelli, H. B. (1986) “Networks: Between Markets and Hierarchies”, Strategic Management Journal, Vol 7 No 1, pp 37-51. 
Today, C. (2003) “Internet Fraud On Rise, FTC Says”, Communications Today, January 24, Vol 9 No 15 , pp $0-1$.

van den Bos, K., van Schie, E.C.M., and Colenberg, S.E. (2002) “Parents' Reactions to Child Day Care Organizations: The Influence of Perceptions of Procedures and the Role of Organizations' Trustworthiness”, Social Justice Research, Vol 15 No 1, pp 53-62.

Zhang, X., and Zhang, Q. (2005) “Online Trust Forming Mechanism: Approaches and an Integrated Model”, 7th International Conference on Electronic Commerce (ICEC'05), 15-17 August 2005, Xi'an, China.

Zhao, X., Fang, F., and Whinston, A.B. (2006) "Designing On-Line Mediation Services for C2C Markets”, International Journal of Electronic Commerce, Vol 10 No 3, pp 71-93.

Zucker, L. G. (1986) "Production of Trust: Institutional Sources of Economic Structure”, Research in Organisational Behaviour, Vol 8, pp 53-111. 